\title{
Graphene Oxide Coatings Deposited on Steel Substrate Using Electrophoretic Deposition and Electrochemical Evaluation of Coatings in Saline Media
}

\author{
Zaeem Ur Rehman ${ }^{1, a}$, Mohsin Ali Raza ${ }^{1, b^{*}}$, Faizan Ali Ghauri ${ }^{1, c}$ \\ Rumasa Kanwal $^{1, \mathrm{~d}}$, Akhlaq Ahmad ${ }^{2, \mathrm{e}}$ and Aqil Inam ${ }^{1, \mathrm{f}}$ \\ ${ }^{1}$ Department of Metallurgy and Materials Engineering, University of the Punjab, Lahore, Pakistan \\ ${ }^{2}$ University of the Engineering and Technology, Lahore, Pakistan \\ a zaeemurrehman6@gmail.com, ${ }^{b^{*}}$ mohsin.ceet@pu.edu.pk, ${ }^{c}$ engrfaizanghauri@hotmail.com, \\ dsana_kanwal00@yahoo.com, edrakhlaq@uet.edu.pk, faqil.ceet@pu.edu.pk
}

Keywords: Graphene, Corrosion, Mild Steel, Electrophoretic Deposition, Electrochemical, Impedance Spectroscopy

\begin{abstract}
In this study graphene coatings were deposited on mild steel substrate using feasible and environmental friendly method. The successful synthesis of graphite oxide was carried by the modified Hummer's method. Graphene oxide (GO) coatings were developed from GO/water suspension using electrophoretic deposition (EPD). The EPD parameters voltage and deposition time were varied to deposit uniform adherent coatings. The coatings were post heat treated at $200{ }^{\circ} \mathrm{C}$ in vacuum for $4 \mathrm{~h}$ to assess the effect on coated samples. GO and GO-EPD coating morphology were characterized using Fourier transform infrared spectroscopy (FTIR), Atomic force microscopy (AFM) and Scanning electron microscopy (SEM). Linear polarization (LPR) and electrochemical impedance spectroscopy (EIS) tests were performed in saline solution to evaluate electrochemical response. Coatings were partially reduced due to removal of oxygen containing functional groups during EPD and post heat treatments. The GO post heat treated coating had better corrosion resistance $\sim 2$ times than that of bare mild steel and higher charge transfer resistance.
\end{abstract}

\section{Introduction}

Mild steel is widely used in engineering applications as it possesses good formability and weldability. It has poor corrosion resistance in saline media which limits its use for certain applications [1]. Corrosion resistance of mild steel should be improved for better service performance in corrosive conditions. There are various methods available commercially for tackling the corrosion problems of mild steel such as corrosion inhibitors, cathodic protection, electrodeposited metallic coatings, organic coatings and paints [2]. Employing coating on steel is considered as a feasible and reliable method for protection of mild steel [3]. Coatings provide physical and chemical barrier between the substrate and corrosive environment. Generally, organic coatings are widely used; however, their performance is limited due to the presence of toxic chemicals and porosity. Therefore, it is always desired to develop environmentally friendly coatings.

Recently, graphene and graphene oxide (GO) coatings are being studied for corrosion protection of metals. Graphene is a sheet of $\mathrm{sp}^{2}$-bonded carbon atoms, it exhibits unique properties such as chemical inertness, excellent electrical conductivity and thermal stability [4]. The $\mathrm{sp}^{2}$ hexagonal distribution of carbon atoms provides an impermeable physical barrier that safeguards metal substrate from environment interaction [3].

Various deposition methods are used for the production of graphene coatings on the metallic and nonmetallic substrates such as chemical vapor deposition (CVD), electrophoretic deposition (EPD), spin coating and spray deposition. Among these methods, CVD technique is commonly used for graphene deposition, but it has certain limitations such as expensive equipment and high temperature. However, EPD is considered as feasible technique for development of graphene or GO coatings using colloidal suspensions [5]. It has various advantages such as short deposition time, simple equipment, low temperature and easy control of coating thickness. 
Various studies have reported the use of graphene or GO to protect metals, few of them are summarized here. Wenting et al. [6] studied deposited GO coatings on $\mathrm{NdFeB}$ magnets and showed that the GO coated samples had better resistance to corrosion in $0.6 \mathrm{M} \mathrm{NaCl}$ solution. Raza et al. [7] studied corrosion behavior of electrophoretically deposited graphene oxide on copper metal and reported ca. $6 \times$ decrease in corrosion rate compared to bare copper. Conversely, Park et al. studied GO coating produced by EPD on mild steel for anti-corrosion performance [8]. They demonstrated that GO showed no effect on corrosion properties of mild steel. The role of underlying substrate on corrosion performance of graphene coatings was evaluated by Kirkland et al. [9]. They found that the corrosion resistance of graphene coatings depends on the metal substrate used. GO coating on mild steel reported so far raise concern on the anti-corrosive behavior of GO coatings, therefore, this topic needs further investigation for development of better understanding of GO coatings' anticorrosion properties. So this study reports corrosion behavior of GO coatings deposited on mild steel. The GO coatings were deposited on mild steel substrate by EPD method and their characterization was carried using linear polarization and electrochemical impedance spectroscopy.

\section{Experimental}

Graphite powder (particles size 120-200 $\mu \mathrm{m}$ ) was used as a precursor for synthesis of graphite oxide, a precursor for GO synthesis. Graphite oxide was synthesized by using improved Hummers method [10]. Briefly, $3 \mathrm{~g}$ of graphite powder was added to mixture of $\mathrm{H}_{3} \mathrm{PO}_{4} / \mathrm{H}_{2} \mathrm{SO}_{4}$ (1:9). Then, $18 \mathrm{~g}$ of $\mathrm{KMnO}_{4}$ was added slowly to the mixture under continuous stirring for $12 \mathrm{~h}$. After, completion of reaction deionized water $(400 \mathrm{ml})$ added to the mixture and titrated with $3 \mathrm{ml}$ $\left(30 \% \mathrm{H}_{2} \mathrm{O}_{2}\right)$. Finally, solution was filtered using filter paper (Whatman) and filtrated residue was washed with $30 \% \mathrm{HCl}$, ethanol and deionized water, several times, to achieve neutral $\mathrm{pH} 7$. The resultant residue was dried at $60{ }^{\circ} \mathrm{C}$ for $12 \mathrm{~h}$ in vacuum oven.

Development of Coatings. Mild steel samples having dimensions $(5 \times 2 \times 0.5 \mathrm{~cm})$ were ground using silicon carbide papers (grit size 320-1000) and surface roughness (after grinding with emery papers of grit size 320-1000) was measured using profilometer (Mitutoyo SJ-201). Arithmetic mean roughness value $(\mathrm{Ra})$ of bare mild steel was found to be $0.70 \mu \mathrm{m}$ Grounded samples were sonicated in ethanol for $5 \mathrm{~min}$ to remove any organic contaminants from surface followed by rinsing with deionized water. As synthesized graphite oxide powder was used to prepare GO suspension by sonication for $2 \mathrm{~h}$ in deionized water. For EPD mild steel samples were made as an anode and stainless steel as cathode and coating parameters were optimized after series of experiments and found to be $10 \mathrm{~V}$ and $20 \mathrm{~s}$. Furthermore, to evaluate the effect of post coating heating EPD-GO samples were heated at $200{ }^{\circ} \mathrm{C}$ for $4 \mathrm{~h}$ under vacuum. The EPD-GO and heated EPD-GO were labeled as "EPD- GO" and "EPD-GO (C2)" hereafter. A schematic diagram of EPD-GO process is shown in Fig 1.

\section{Characterization}

X-ray diffraction (XRD) of intercalated graphite oxide powder was performed by PANalytical diffractometer to confirm the oxidation. The thickness of graphene nanosheets was measured by atomic force microscopy (NT-MDT AFM). Dilute GO/water suspension was deposited on mica and images were taken in semi-contact mode. Scanning electron microscopy (SEM) was performed to study the morphology and uniformity of coatings. Energy dispersive x-ray spectroscopy (EDS) was carried out with EDAX (Ametek, Inc. Materials Analysis Division) system consisting of solid state silicon drift detector (SDD) using TEAM software. Fourier transform infrared spectroscopy (FTIR) was used to analyze the presence of oxygen-containing functional groups.

Electrochemical studies were carried out in three electrode system using Potentiostat (Reference 3000, Gamry Instruments). Mild steel samples were made working electrode, platinum (Pt) wire as counter electrode and saturated calomel electrode (SCE) was used as reference electrode. Linear polarization was performed in the range of -0.02 to $0.02 \mathrm{~V}$ at a scan rate of $1 \mathrm{mV} / \mathrm{s}$ in $3.5 \% \mathrm{NaCl}$ 
solution. Electrochemical impedance spectroscopy (EIS) was performed in the frequency range of $0.01 \mathrm{~Hz}$ to 100 $\mathrm{kHz}$. Echem analyst software version 6 was used to calculate electrochemical parameters.

\section{Results and Discussions}

GO and Coatings Analysis. Fig. 2 (a) shows the XRD pattern of graphite powder and intercalated graphite oxide. Graphite powder exhibits a peak at $26.32^{\circ}$ which corresponds to (002) plane of graphite. Due to oxidation of the graphite, the peak at $26.32^{\circ}$ vanishes and broad peak appears at $11.40^{\circ}$ corresponds to plane (001). The increase in d-spacing due to intercalation of graphite and attachment of functional groups at basal planes and edges of graphite planes revealed satisfactory oxidation of graphite powder $[10,11]$. The well- dispersed suspension of GO in deionized water was spin-coated on mica and then was analyzed by semi contact mode AFM as shown in Fig. 2 (b). The AFM image exhibits that graphene sheet has thickness of approx. $1.5 \mathrm{~nm}$. Furthermore, the lateral dimension of GO sheets was in the range 250- 500 $\mathrm{nm}$ although some smaller sheets were also observed.

Fig. 3 (a) shows FTIR spectra of GO, EPD-GO and EPD-GO (C2). An infrared spectrum of GO suggests successful oxidation of pristine graphite as it showed peaks which relate to functional groups such as hydroxyl

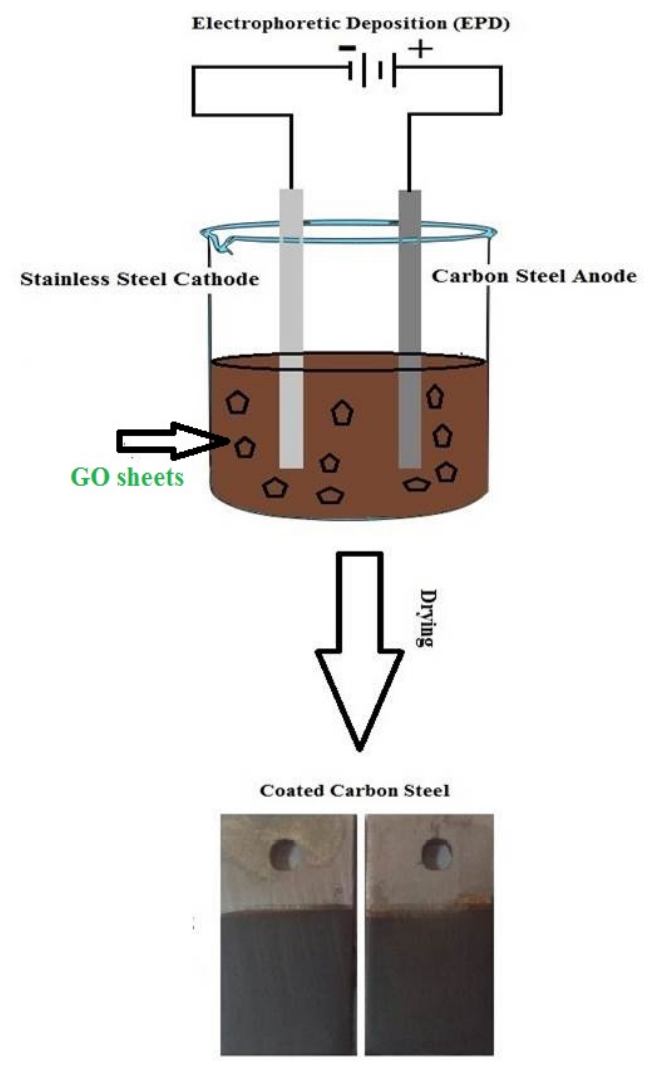

Fig. 1 Schematic of EPD process for production of GO coatings on mild steel $(-\mathrm{OH})$, carboxylate $(-\mathrm{COOH})$ and epoxide $(=\mathrm{CO})$ at basal and peripheries of basal planes of GO. On the other hand, EPD-GO had lower transmittance peaks of functional groups and hydroxyl $(-\mathrm{OH})$ group peak almost vanished due to partial reduction of GO occurred during EPD process as suggested by An et al.[12]. Furthermore, they proposed that negatively charged GO sheets migrate to the anode will find unpaired electrons to form covalent bond. Thermally reduced EPD-GO (C2) coating had peaks at $1050 \mathrm{~cm}^{-1}(\mathrm{C}-\mathrm{O})$ and $1555 \mathrm{~cm}^{-1}(\mathrm{C}=\mathrm{O})$ which suggest an effective thermal reduction of $\mathrm{GO}$ and restoration of $\pi$ network [13].

EPD-GO and EPD-GO (C2) coatings have similar thicknesses $(\sim 3 \mu \mathrm{m})$ which were produced at similar optimum EPD parameters (voltage \& time) and according to Hamaker's model for EPD [14]. Fig. 3(b) displays EPD-GO (C2) coating thickness measured from coating metal interface. SEM images of EPD-GO and EPD-GO (C2) along with EDX spectrum are shown in Fig. 3 (c, d). The EPD-GO coating was almost uniform stacks of GO sheets with occasional wrinkles and acquired complete coverage of mild steel. On the other hand, EPD-GO (C2) coating was crumbled and has exfoliated GO morphology. Furthermore, EDX spectrum of EPD-GO (C2) had a high content of carbon than EPD-GO which confirmed reduced GO layers were well formulated on the surface of mild steel which was in agreement with FTIR findings. Some peaks of iron from the substrate were also present in EDX spectrum. 

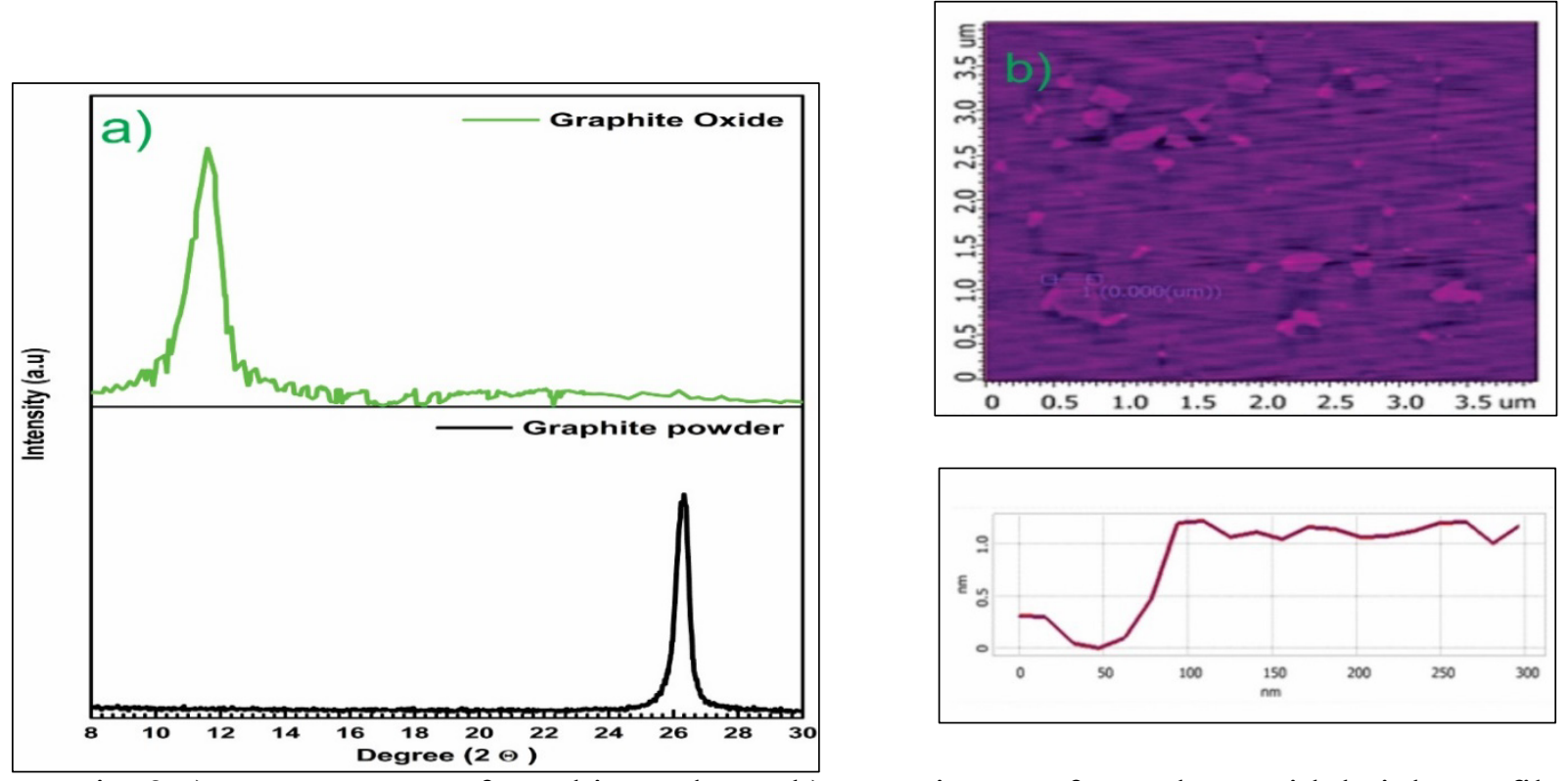

Fig. 2 a) XRD patterns of graphite and GO, b) AFM image of GO along with height profile

\section{Corrosion Study}

Linear Polarization Resistance (LPR). Fig. 4 shows the linear polarization curves of bare mild steel, EPD-GO and EPD-GO (C2). Corrosion rates of samples calculated using Gamry Echem Analyst software are presented in Table 1. It was revealed that EPD-GO coating on mild steel has no appreciable effect on corrosion resistance and negative shift of $\sim 38 \mathrm{mV}$ in corrosion potential ( $\left.E_{\text {corr }}\right)$ was observed. Similar results were previously obtained by Park et al. [8] for EPD-GO coating on mild steel and reported a negative shift in $\mathrm{E}_{\text {corr }}$ with no benefit for corrosion protection. The insignificant corrosion performance of EPD-GO could be due to hydrophilic nature of GO and damaged structure of GO formed during oxidation of GO, which acts as sites for the corrosive electrolyte to penetrate.

On the other hand, EPD-GO (C2) showed better corrosion resistance than that of bare metal and reduced the corrosion rate $\sim 2 \times$ with a positive shift in $\mathrm{E}_{\text {corr }}$ of ca. $30 \mathrm{mV}$. It was reported before that reduced graphene oxide (rGO) resulted in hydrophobic and denser graphitic structure [15] which could be the reason for the superior performance of EPD-GO (C2). Furthermore, Jin et al. [16] reported that the thermal reduction of GO coatings could increase the adhesion of coatings by forming chemical bond between metallic substrate and $\mathrm{GO}(\mathrm{C}-\mathrm{O}-\mathrm{Fe})$ due to possible breakage of $\mathrm{C}=\mathrm{O}$ as observed in Fig 3.(a), and this might be the reason for better corrosion resistance of EPD$\mathrm{GO}(\mathrm{C} 2)$.

Electrochemical Impedance Spectroscopy (EIS). To validate and further analyze the performance of EPD-GO (C2) electrochemical impedance spectroscopy (EIS) was conducted at open circuit potential (OCP) after stability achieved after $3600 \mathrm{~s}$ with an alternating potential amplitude of $\pm 10 \mathrm{mV}$ in the frequency range of $0.01 \mathrm{~Hz}$ to $100 \mathrm{kHz}$. Nyquist plots $\left(Z_{\text {real }}\right.$ Vs. $\left.-Z_{\text {img }}\right)$ of bare mild steel and EPD-GO (C2) are shown in Fig. 5 (b). The modulus of impedance $|Z|$ calculated from low-frequency regime tells about the resistance to charge transfer [17]. EPD-GO (C2) exhibits a higher $|\mathrm{Z}|$ of $318.4 \Omega * \mathrm{~cm}^{2}$ than that of bare mild steel as shown in Fig. 5 (a). The anti-corrosive nature of EPD-GO $(\mathrm{C} 2)$ acted as a barrier for the electrolyte to reach the underlying substrate and increased the oxidation resistance of the mild steel.

To further understand the electrochemical processes of the EPD-GO (C2) and bare mild steel the equivalent electrical circuit (ECC) model was well fitted to the curves. Fig. 5 inset shows the ECC model and circuit elements were designated as solution resistance $\left(\mathrm{R}_{\mathrm{s}}\right)$, charge transfer resistance $\left(\mathrm{R}_{\mathrm{ct}}\right)$, coating capacitance $\left(\mathrm{C}_{\mathrm{C}}\right)$ and double layer capacitance $\left(\mathrm{C}_{\mathrm{dl}}\right)$. 

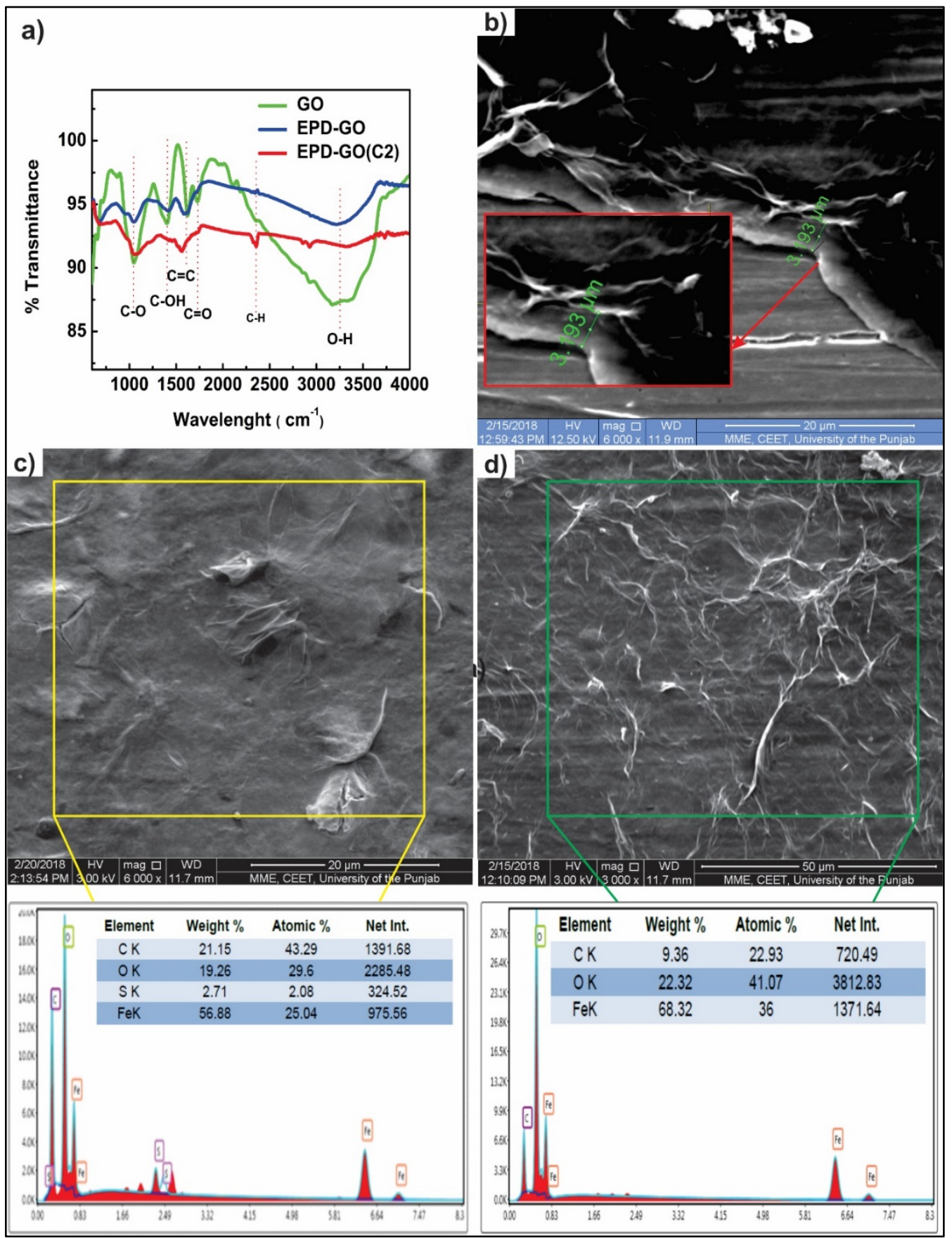

Fig. 3 (a) FTIR spectra of GO, EPD-GO and EPD-GO (C2), (b) Coating thickness of EPD-GO, and (c \& d) SEM images of EPD-GO and EPD-GO (C2) respectively along with EDX analysis

Table 1 Corrosion rate calculated from linear polarization curves

\begin{tabular}{lccc} 
Sample & $\begin{array}{c}\mathrm{I}_{\text {corr }} \\
\left(\mu \mathrm{A} / \mathrm{cm}^{2}\right)\end{array}$ & $\begin{array}{c}\mathrm{E}_{\text {corr }} \\
(\mathrm{mV})\end{array}$ & $\begin{array}{c}\text { Corrosion rate } \\
(\mathrm{mpy})\end{array}$ \\
Bare mild steel & 94.6 & -617 & 43.6 \\
EPD-GO & 81.8 & -659 & 37.7 \\
\hline EPD-GO (C2) & 55.4 & -586 & 24.1 \\
\hline
\end{tabular}


The electrical circuit elements' calculated values are presented in Table 2. The constant phase element was used for the better fitting of the data due to non-ideal behavior of the coating which is represented by two factors: admittance (Yo) and $\mathrm{n}$. The capacitance of the system was calculated according to Eq. 1 .

$$
C=Y_{o}\left(\omega_{\max }^{n}\right)^{\mathrm{n}-1}
$$

The higher $\mathrm{R}_{\mathrm{ct}}\left(676 \Omega^{*} \mathrm{~cm}^{2}\right)$ for EPD-GO (C2) was due to high resistance to adsorption and desorption of charge species present at GO surface. Double layer phenomena at intermediate frequency regime tell about the presence of the active sites for the corrosion reactions to occur and distribution of charges

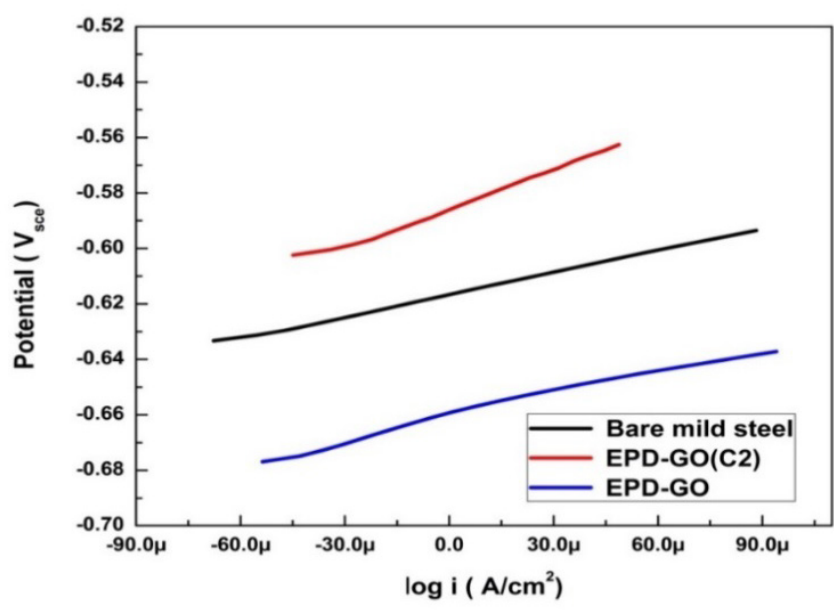

Fig. 4 Linear Polarization curves of bare mild steel and coatings in $3.5 \% \mathrm{NaCl}$ solution [18], lower value was calculated for EPD-GO (C2). It suggested that EPD-GO (C2) had good coverage of the active sites and validated the LPR findings. Lastly, to a certain extent, similar electrochemical processes occurred for both coatings which leads to the conclusion that GO coatings were imperfect.

Table 2 ECC values obtained after fitting of the data

\begin{tabular}{lcccccc}
\hline Sample & $\begin{array}{c}\mathrm{R}_{\mathrm{sol}} \\
\left(\Omega^{*} \mathrm{~cm}^{2}\right)\end{array}$ & $\begin{array}{c}\mathrm{R}_{\mathrm{ct}} \\
\left(\Omega^{*} \mathrm{~cm}^{2}\right)\end{array}$ & $\begin{array}{c}\mathrm{R}_{\mathrm{po}} \\
\left(\Omega^{*} \mathrm{~cm}^{2}\right)\end{array}$ & $\begin{array}{c}\mathrm{C}_{\mathrm{c}} \\
\left(\mathrm{mFcm}^{2}\right)\end{array}$ & $\begin{array}{c}\mathrm{C}_{\mathrm{dl}} \\
\left(\mathrm{mF} \mathrm{cm}^{2}\right)\end{array}$ & $\begin{array}{c}\text { Goodness of } \\
\text { Bit }\end{array}$ \\
Eare mild steel & 8.2 & 600 & 1.4 & 8.1 & 15.1 & $298.9 \mathrm{e}-6$ \\
\hline
\end{tabular}

\section{Conclusions}

In the present work, GO coatings were produced on mild steel by EPD process and their corrosion studies were carried out in saline media. It was found that EPD-GO coatings heated at $200^{\circ} \mathrm{C}$ were fully reduced due to an absence of functional groups however, as deposited EPD-GO coatings were only partially reduced as many functional groups were observed by FTIR analysis. The EPDGO (C2) coatings reduced at $200^{\circ} \mathrm{C}$ lowered the corrosion rate of mild steel by ca. $2 \times$ as determined by LPR analysis. EIS of the same coatings showed higher charge resistance of the coating compared to mild steel and also drop in the $\mathrm{C}_{\mathrm{dl}}$ value suggesting the less accumulation of charges around the coating and reduced ingress of electrolyte through the coating to the underlying layer.
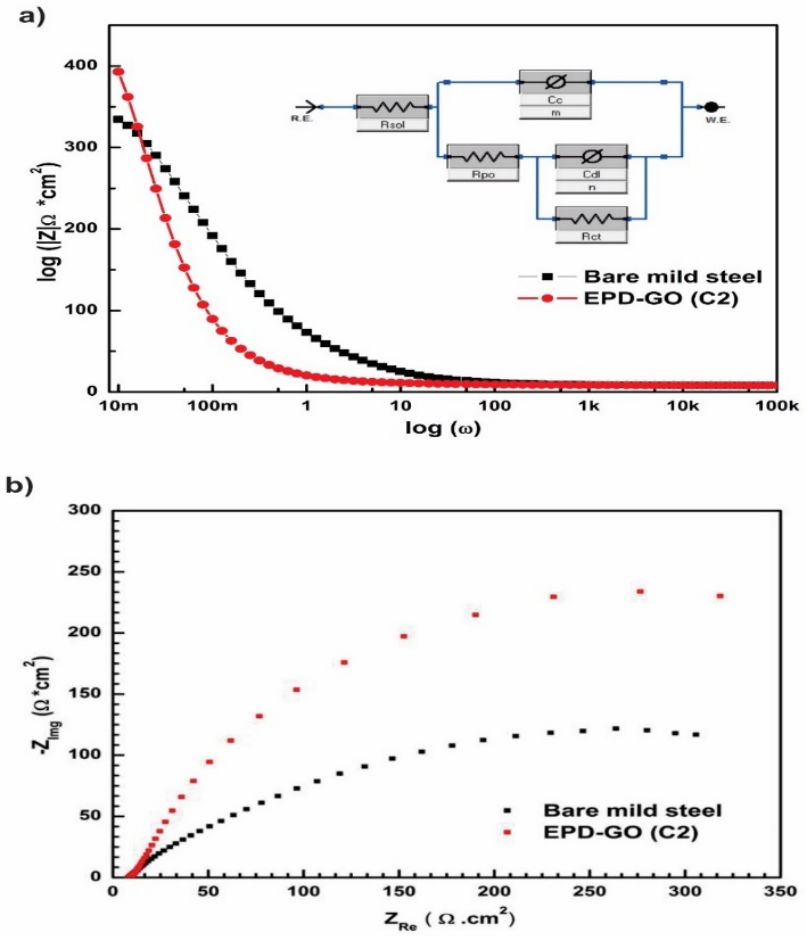

Fig. 5 (a) Bode plot and equivalent circuit of bare mild steel and EPD-GO (C2) in 3.5\% NaCl, b) Nyquist plot 


\section{Acknowledgment}

The author would like to thank Higher Education Commission of Pakistan (grant No. 3283) for providing financial assistance to carry out this research work.

\section{References}

[1] M.M. El Rayes, H.S. Abdo, and K.A. Khalil, Erosion-corrosion of cermet coating. International J. Electrochem. Sci., 8 (2013) 117-121.

Z.W. Wicks Jr, et al., Organic coatings: science and technology. 2007: John Wiley \& Sons.

[2] J.S. Bunch, et al., Impermeable atomic membranes from graphene sheets. Nano Lett., 8 (2008) 2458-2462.

[3] L., Liu, et al., Graphene oxidation: thickness-dependent etching and strong chemical doping. Nano Lett., 8 (2008) 1965-1970.

[4] L. Besra, and M. Liu, A review on fundamentals and applications of electrophoretic deposition (EPD). Prog. Mater. Sci., 52 (2007) 1-61.

[5] W. He, et al., Electrophoretic deposition of graphene oxide as a corrosion inhibitor for sintered NdFeB. App. Sur. Sci., 279 (2013) 416-423.

[6] M.A. Raza, et al., Corrosion study of electrophoretically deposited graphene oxide coatings on copper metal. Thin Sol. Fil., 620 (2016) 150-159.

[7] Ji Hoon Park, J.P., Electrophoretic deposition of graphene oxide on mild carbon steel for anticorrosion application. Surf. Coat. Technol., 26 (2014) 321-329.

[8] N. Kirkland, et al., Exploring graphene as a corrosion protection barrier. Corr. Sci., 56 (2012) 1-4.

[9] D.C.,Marcano, et al., Improved synthesis of graphene oxide. ACS Nano, 4 (2010) 4806-4814.

[10] S., Hong, et al., Dielectrophoretic deposition of graphite oxide soot particles. J. Nanosci. Nanotech., 8 (2008) 424-427.

[11] S.J. An, et al., Thin film fabrication and simultaneous anodic reduction of deposited graphene oxide platelets by electrophoretic deposition. The J. Phy.l Chem. Lett., 1 (2010) 1259-1263.

[12] W. Gao, The chemistry of graphene oxide, in Graphene oxide. 2015, Springer. p. 61-95.

[13] H. Hamaker, Formation of a deposit by electrophoresis. Trans. Farad. Soc., 35 (1940) 279287.

[14] G.B. Olowojoba, et al., In situ thermally reduced graphene oxide/epoxy composites: thermal and mechanical properties. App. Nanosci., 6 (2016) 1015-1022.

[15] S. Jin, et al., Interfacial development of electrophoretically deposited graphene oxide films on Al alloys. J.The Electrochem.1 Soc., 162 (2015) D3025-D3029.

[16] S.-M Park,. and J.-S. Yoo, Peer reviewed: electrochemical impedance spectroscopy for better electrochemical measurements, Anal. Chem., 75 (2003) 455 A-461 A

[17] I. Sekine, Recent evaluation of corrosion protective paint films by electrochemical methods. Prog. Org. Coat., 31 (1997) 73-80. 